\title{
¿CUIDADO PERSONAL A PARTIR DEL RÉGIMEN DE RELACIÓN DIRECTA Y REGULAR? \\ LA IMPORTANCIA DEL DERECHO \\ INTERNACIONAL Y COMPARADO
}

PERSONAL CARE ROOTED

IN THE SYSTEM OF DIRECT

AND REGULAR CONTACT?

THE IMPORTANCE OF INTERNATIONAL

AND COMPARATIVE LAW

\section{CUIDADO PESSOAL A PARTIR DO REGIME DE RELAÇÃO DIRETA E REGULAR? A IMPORTÂNCIA DO DIREITO INTERNACIONAL E COMPARADO}

Viviane I. Lennon González:

Domingo A. Lovera Parmo**

\section{Resumen}

Para el Derecho doméstico aparece clara la diferencia entre titularidad del derecho al cuidado personal y los derechos de mantener un régimen de relación directa y regular. Dichos contornos se alteran, sin embargo, a la luz de la Convención de la Haya sobre los Aspectos Civiles de la Sustracción de Menores. Dichas alteraciones se analizan en este trabajo, donde se llama la atención sobre la deficiente práctica jurisprudencial nacional.

* Licenciada en Ciencias Jurídicas y Sociales, Universidad Diego Portales y diplomada en Responsabilidad Civil, Contractual y Extracontractual, Universidad de Chile. Dirección postal: Huérfanos 770, oficina 2303, Santiago. Artículo recibido el 21 de marzo de 2011 y aceptado para su publicación el 26 de septiembre de 2011. Correo electrónico: vlennon@horvitz.cl.

${ }^{* *}$ Licenciado en Ciencias Jurídicas y Sociales, Universidad Diego Portales y Ll.M. Columbia University. Profesor de Derecho Constitucional, Universidad Diego Portales. Dirección Postal: República 105. Artículo recibido el 21 de marzo de 2011 y aceptado para su publicación el 26 de septiembre de 2011. Correo electrónico: domingo.lovera@udp.cl. 
Palabras clave: Derecho ne exeat, cuidado personal, relación directa y regular, Convención Internacional de la Haya.

\begin{abstract}
Within the realm of Chilean law, the difference between having the right to personal care and the right to a system of direct and regular contact seems to be clear and evident. However, such difference varies in the light of the Hague Convention on the Civil Aspects of International Child Abduction. Those variations will be analyzed in this paper, which highlights the inadequate case law practice in Chile.
\end{abstract}

Keywords: Ne exeat right, Personal care, Direct and regular contact, International Hague Convention.

\title{
Resumo
}

Para o direito doméstico aparece clara a diferença entre titularidade do 106 direito ao cuidado pessoal e os direitos de manter um regime de relação direta e regular. Ditos contornos se alteram, embora, à luz da Convenção da Haya sobre os Aspectos Civis da Sustração de Menores. Ditas alterações se analisam neste trabalho, onde se chama a atenção sobre a deficiente prática jurisprudencial nacional.

Palavras chave: Direito ne exeat, cuidado pessoal, relação direta e regular, Convenção Internacional da Haya.

\section{INTRODUCCIÓN}

Las relaciones entre el Derecho Internacional y el Derecho Doméstico han sido parte de las discusiones más relevantes en el Derecho contemporáneo. Ese debate ha girado, principalmente, en torno a dos temas, distintos, pero muy relacionados:

- en primer lugar, las relaciones entre el derecho internacional (entendido a grosso modo como un derecho que busca regular las relaciones entre los Estados, y entre éstos y sus habitantes $)^{1}$ y el Derecho Doméstico y

${ }^{1}$ Anthony Aust, Handbook of International Law, Cambridge, Cambridge University Press, 2010, p. 2. 
- en segundo lugar, la importancia (y legitimidad de la práctica) de mirar a las instancias comparadas de adjudicación, a efectos de resolver discusiones de Derecho interno.

Respecto al segundo punto, esto es, en lo relativo a la legitimidad de la práctica que mira a la forma en que otras jurisdicciones han resuelto asuntos legales que son igual de relevantes para nuestra comunidad, se ha sugerido que dicha observancia favorece la búsqueda de soluciones comunes. Si las decisiones legales son una cuestión de razonamiento -más que pura expresión de deseos o voluntad- entonces, mirar a la forma en que otras jurisdicciones han resuelto asuntos similares a los que debemos decidir supone asumir una suerte de enfoque científico donde la respuesta a nuestros problemas legales descansa, no sólo en nuestro razonamiento sino "en una relación racional entre los que debemos resolver y la forma en que otros han resuelto al respecto" .

Este enfoque científico se ve favorecido por los tratados y convenciones internacionales. Y se favorece porque hay un punto común de arranque-el texto autoritativo del tratado o Convención-sobre el cual las diferentes jurisdicciones van arrojando sus lecturas. Que dichas lecturas deban coincidir o no puede ser pura contingencia, es cierto. Pero cuando la concurrencia de interpretaciones de un tratado o Convención es uno de los objetivos que los adherentes establecieron, la concurrencia se transforma en un deber. La lectura e interpretación armónica de estos instrumentos -que intenta dar respuestas comunes a problemas jurídicos igualmente compartidos-debe buscarse y promoverse ${ }^{3}$.

La sentencia, cuyo comentario ahora comenzamos, posee particular relevancia para este enfoque científico, al tiempo que honra los compromisos de los Estados signatarios de la Convención de la Haya ${ }^{4}$. Queremos llamar la atención sobre los compromisos que el Estado de Chile ha adoptado voluntariamente en materia de tratamiento del secuestro internacional de niños y niñas. Advertiremos cómo ese compromiso, esto es, la palabra empeñada del Estado en el ámbito internacional, condiciona su actuar en

2 Jeremy Waldron, "Foreign Law and the Modern Ius Gentium", in Harvard Law Review, vol. 119, No 1, Cambridge, 2005, pp. 146-147.

${ }^{3}$ Como lo afirma Linda Silberman, la uniformidad de interpretación es un aspecto crítico de la Convención en comento, toda vez que busca erigirse como un mecanismo de cooperación entre los estados para desincentivar y remediar los secuestros internacionales de niños y niñas. Linda Silberman, "Interpreting the Hague Abduction Convention: In Search of a Global Jurisprudence", in New York University Public Law and Legal Theory Working Papers. Paper 18, New York, 2006, p. 10, disponible en: http://lsr.nellco.org/nyu_plltwp/18, visitada el 20 de enero de 2011.

${ }^{4}$ Nos referimos a la Convención, 25 de octubre de 1980, La Haya, en vigor en Chile desde el 1 de mayo de 1994, Diario Oficial, 17 de junio de 1994, http://hcch.e-vision.nl/ index_en.php?act=conventions.status\&cid=24, visitada el 20 de enero de 2011. 
ciertas áreas que identificamos más adelante. Con mayor énfasis quisiéramos sugerir que nuestras Cortes debieran estar atentas al impacto que las convenciones internacionales suscritas poseen en el Derecho Doméstico. Este trabajo sostiene que el titular del derecho a la relación directa y regular - al amparo de la Convención de la Haya- podría ampliar sus facultades hacia aquéllas que son propias del cuidado personal, insistimos, en las áreas de aplicación definidas por la misma.

Para lo anterior, el plan es el que sigue: la sección siguiente (II) está destinada a repasar la legislación doméstica sobre los derechos de cuidado personal y a mantener una relación directa y regular. Queremos detallar, en especial, cómo la legislación y la jurisprudencia han venido delimitando las facultades que cada uno de estos derechos entregan a sus titulares. Especial énfasis se colocará en aquélla que asiste al padre o madre que no goza del derecho al cuidado personal para, sin embargo, autorizar la salida de su hijo o hija al extranjero (lo que se denomina derecho ne exeat). En la sección III analizaremos la decisión de la Corte Suprema de Estados Unidos para el caso Abbott v. Abbott ${ }^{5}$. Este caso es importante, sostendremos, debido a que se pronuncia sobre derechos ya establecidos al amparo de procedimientos judiciales internos en el contexto de la aplicación de la Convención de la Haya, ampliando-sobre la base, y en línea, de la misma-su alcance. En la sección IV advertiremos sobre la forma en que nuestra jurisprudencia ha venido resolviendo casos sobre secuestro internacional. Advertiremos que la excesiva importancia que nuestros tribunales prestan a las excepciones de la Convención, subvierte los principios fundantes de la misma y convierten a Chile en un Estado que se aparta de las interpretaciones uniformes. Reservamos algunas conclusiones para la sección final (v).

\section{El Derecho ChILENO: RELACIÓN DIRECTA Y REGULAR SIN CUIDADO PERSONAL}

A efectos de analizar la sentencia en comento, cabe revisar cuál es el marco normativo existente respecto de las materias de cuidado personal y relación directa y regular en la legislación chilena. Ello nos permitirá determinar cuáles son las atribuciones que la ley le otorga a los padres para definir aspectos relevantes de la vida de sus hijos. Distinguidos ambos conceptos analizaremos cómo, de acuerdo con el razonamiento seguido en Abbott, puede concluirse que el derecho ne exeat de uno de los padres le confiere facultades que históricamente han estado ligadas a quien goza del derecho

${ }^{5}$ Abbott $v$. Abbott. La versión utilizada en este artículo se encuentra disponible online en: http://www.supremecourt.gov/opinions/09pdf/08-645.pdf. 
al cuidado personal. De esta forma, queremos insistir cómo -en el marco de la Convención- se derriba la concepción que asume que todas las decisiones relevantes en la vida de los hijos pueden ser adoptadas sólo por el padre titular del derecho al cuidado personal.

\section{1) Marco normativo}

El art. 224 del $C C$ dispone que corresponde a los padres, o al padre o madre sobreviviente el cuidado personal de la crianza y educación de los hijos. Por su parte, el art. 225 del mismo cuerpo legal agrega que, en caso que los padres vivan separados, a la madre tocará el cuidado personal. Se establece, ahí mismo, la posibilidad de alterar dicha regla ya sea mediante acuerdo solemne de los padres en el que se establezca que dicho cuidado corresponderá al padre, o por medio de sentencia judicial "cuando el interés del hijo lo haga indispensable, sea por maltrato, descuido u otra causa calificada". Es decir, el Derecho chileno sólo contempla la posibilidad de un cuidado personal compartido por los padres para el caso en que la filiación del hijo se encuentre determinada respecto de ambos padres, y únicamente mientras éstos vivan juntos. Carece de reconocimiento en nuestro ordenamiento jurídico la institución del cuidado personal (tuición) compartido, y la ley prevé una regla supletoria de atribución preferente a la madre, en el caso de separación y que no exista acuerdo diverso entre los padres.

No obstante, la ley sí reconoce y garantiza que aquel niño cuyos padres se encuentran separados mantenga un contacto directo y regular con aquél de los padres con quien no viva, derecho reconocido, por lo demás, en la Convención sobre los Derechos del Niño, art. $9 \mathrm{~N}^{\circ} 3$. Es así que el art. 229 del $C C$ dispone:

"el padre o madre que no tenga el cuidado personal del hijo, no será privado del derecho ni quedará exento del deber, que consiste en mantener con él una relación directa y regular, la que ejercerá con la frecuencia y libertad acordada con quien lo tiene a su cargo, o, en su defecto, con las que el juez estimare conveniente para el hijo.

Se suspenderá o restringirá el ejercicio de este derecho cuando manifiestamente perjudique el bienestar del hijo, lo que declarará el tribunal fundadamente".

Por tanto, regirá en esta materia lo regulado por los padres de común acuerdo o, si no se produce, por lo que un juez determine en una causa en la cual se solicite regular un régimen de relación directa y regular, ya sea por la madre o por el padre que no conviva junto al hijo(a). Una con- 
sideración primordial y principio rector en el derecho de familia es el del interés superior del niño, que ha sido entendido como la satisfacción plena de sus derechos fundamentales ${ }^{6}$. Esta disposición, una vez más, coincide con el mandato de la Convención sobre los Derechos del Niño, la que dispone en su art. $3 \mathrm{~N}^{\circ} 1$

"en todas las medidas concernientes a los niños que tomen las institu-
ciones públicas o privadas de bienestar social, los tribunales, las auto-
ridades administrativas o los órganos legislativos, una consideración
primordial a que se atenderá será el interés superior del niño"7.

\section{2) Distinguiendo conceptos}

La ley chilena distingue claramente el cuidado personal del régimen de relación directa y regular. Mientras el primero supone ejercer la crianza y la educación del hijo $(a)^{8}$, el segundo se entiende como el derecho del hijo(a) a mantener un contacto regular con su padre o madre con el cual no convive. Son estos conceptos - que pareciesen ser tan disímiles en la legislación chilena y delimitados en cuanto a las facultades- los que creemos que deben revisarse a la luz de la sentencia en comento, en virtud de 110 las observaciones que se hacen a continuación:

- En primer lugar, la ley no define qué se entiende por uno u otro concepto. No obstante, constituye una noción acuñada por la doctrina que el cuidado personal hace referencia a la "convivencia física habitual con el menor" ${ }^{\prime}$, y el régimen comunicacional, el derecho del hijo a mantener un contacto permanente y regular con aquel de los padres con quien no vive, y que otorga también la acción a aquel de los progenitores que carece del cuidado personal para demandarlo. Todo lo anterior bajo el entendimiento de que la ley reconoce el principio que para el desarrollo integral de todo niño y

${ }^{6}$ Miguel Cillero, "Interés superior del niño en el marco de la Convención Internacional sobre los Derechos del Niño", en Revista Justicia y Derechos del Niño, vol. 1, Santiago, 1999, pp. 134-136.

${ }^{7}$ Manuel Martínez Guillén con Georgina Pérez de Arce Morcom, Corte de Apelaciones de San Miguel de fecha 15 de mayo del año 2001.

${ }^{8} \mathrm{El}$ art. 224 del $C C$ establece: "toca de consuno a los padres, o al padre o madre sobreviviente, el cuidado personal de la crianza y educación de sus hijos". Por su parte, el art. 5 de la Convención de la Haya, define el derecho de tuición como aquél que comprenderá "el derecho relativo a los cuidados de la persona del niño y, en particular, el derecho a determinar su lugar de residencia".

${ }^{9}$ María Jesús Monfort, "Algunas cuestiones civiles en torno a la sustracción de menores en el ambito familiar", en Paz LlORia (ed.), Secuestro de menores en el ámbito familiar: un estudio interdisciplinar, Madrid, Iustel, 2008, p. 125. 
la formación de su identidad, resulta esencial mantener un contacto regular y cercano con ambos padres.

- En segundo lugar, de la falta de delimitación de ambos conceptos surgen algunas preguntas tales como si acaso el derecho a mantener un contacto directo y regular supone sólo el derecho a visitar al hijo periódicamente; si acaso puede aquel de los padres que no es titular del derecho al cuidado personal interferir de forma directa en las decisiones relativas a la vida del hijo (por ejemplo, participando en la elección de su colegio, intervenir respecto de la elección de su tratamiento médico o decidir lugar de residencia del mismo), entre otras. Dicha discusión ocurre en el contexto de la ausencia de un instituto que regule las facultades del padre no custodio para intervenir en las decisiones relevantes que deban adoptarse respecto del niño. Lo anterior se agrava aún más, considerando lo indicado por María Rodríguez, esto es, que con las leyes $\mathrm{N}^{\mathrm{os}} 18.802$, de 1989 -por medio de la cual se estableció que la madre detentaría el cuidado personal de todos los hijos menores de edad-y 19.585, de 1998 -de acuerdo con la cual, la patria potestad se radicará en quien tenga el cuidado personal, salvo acuerdo o resolución judicial en contrario- se llegó al extremo, "al excluir al progenitor privado del cuidado personal de decisiones importantes relativas al hijo"10. Ya que, al menos antes de dicha modificación legal, en caso de separación, el padre, a pesar de no conseguir el cuidado personal, mantenía también la patria potestad. Al efecto, María Rodríguez señala

“es cierto que los artículos 222, 230, 234 y 236 entregan a ambos padres, vivan o no juntos, la preocupación por el interés superior del hijo (artículo 222), los gastos de educación, crianza y establecimiento de los hijos (artículo 230), la facultad de corregir a los hijos (artículo 234), y el derecho y el deber de educar a los hijos (artículo 236). Pero en los hechos, estas atribuciones las ejerce quien tiene el cuidado personal y no se conocen casos (exceptuando el asunto de los gastos) en que el padre o madre privado de la tuición pretenda el ejercicio de atribuciones en el ámbito de la corrección o educación del hijo"11.

Sin perjuicio de lo anterior, en la actualidad existe una tendencia a sostener, de forma mayoritaria, que el derecho de mantener un

${ }^{10}$ María Rodríguez, Cuidado personal de niños y adolescentes en el nuevo Derecho chileno de Familia, Santiago, Abeledo Perrot Legal Publishing, 2010, p. 97.

${ }^{11}$ Op. cit., p. 97, n. 153. 
régimen comunicacional no sólo implica el asegurar un contacto y comunicación entre alguno de los padres y el hijo sino que el derecho del primero de participar activamente en decisiones relevantes en su vida ${ }^{12}$.

Ello, además, resulta concordante con lo dispuesto en el art. 18 $\mathrm{N}^{\circ} 1$ de la Convención sobre los Derechos del Niño. Dicho precepto, que reconoce el principio de corresponsabilidad parental, dispone

“[1]os Estados Partes pondrán el máximo empeño en garantizar el reconocimiento del principio de que ambos padres tienen obligaciones comunes en lo que respecta a la crianza y el desarrollo del niño...”.

Dicho principio de corresponsabilidad parental consiste, según Fabiola Lathrop, "en el reparto equitativo de los derechos y deberes que los progenitores deben ejercer frente a sus hijos" ${ }^{13}$. La autora indica que este principio se encuentra recogido en el art. 224 del $C C$, que señala que corresponde a los padres, o al padre o madre sobreviviente, "el cuidado personal de la crianza y educación de los hijos", debiendo entenderse así que este deber genérico corresponde a ambos padres conjuntamente, sin perjuicio que la misma indica que ello no se encontraría concretado en nuestra legislación.

De esta manera, puede afirmarse que, quien carezca del cuidado personal del hijo, no queda excluido del ejercicio conjunto de ciertas atribuciones respecto a la toma de decisiones que puedan afectar la vida de éste, criticándose así que deba

“conformar[se] con un derecho de visita más o menos amplio (habitualmente limitado a los fines de semana), aquejado inevitablemente de superficialidad y carencias afectivas (falta de confianza

${ }^{12}$ Corte de Apelaciones de Santiago, en Revista Derecho y Jurisprudencia, No 2, Santiago, 2004, sec. $2^{\text {a }}$, p. 92. "Luego de las modificaciones introducidas por la Ley $\mathrm{N}^{\mathrm{o}}$ 19.585.-, el régimen de visitas no se condice sólo como un derecho del padre o madre que no tiene la custodia personal del hijo para visitarlo, sino como un deber que mira al interés del menor, para mantener con él una relación directa y regular, lo que está en perfecta concordancia con lo preceptuado en el artículo 236 del Código Civil, que recogiendo el principio consagrado en el artículo $19 \mathrm{~N}^{\circ} 10$, inciso $3^{\circ}$ de la Constitución Política de la República dispone que los padres tendrán el derecho y el deber de educar a sus hijos orientándolos hacia su pleno desarrollo en las distintas etapas de la vida".

${ }^{13}$ Fabiola Lathrop, "La corresposabilidad parental", en Carlos PiZARro Wilson, Estudios de Derecho Civil: IV Jornadas de Derecho Civil, Santiago, Abeledo Perrot Legal Publishing, 2009 , p. 213. 
entre el padre y el hijo, escasa participación del uno en la vida del otro, etc.)" ${ }^{14}$.

- En tercer orden de ideas, debe reconocerse que la falta de claridad respecto de la extensión de este derecho de mantener un régimen comunicacional y de ejercer la autoridad paterna, conjugado con la limitante legal de que el cuidado personal del hijo -y, por tanto, la crianza del mismo - corresponde únicamente a uno de los padres en el caso que vivan separados, plantea la dificultad de hacer exigible ante el órgano jurisdiccional el derecho del padre no custodio de intervenir en la vida del niño (principio de la corresponsabilidad parental). No obstante la oscuridad de las facultades que entraña cada derecho, sí es posible concluir que el derecho de relación directa y regular debe entenderse de un modo más restringido que el cuidado personal.

Lo anterior, sin embargo, en ningún caso quiere decir que el padre titular del derecho al cuidado personal posea facultades exorbitantes. En efecto, la legislación chilena contempla expresamente una norma que limita las facultades de aquel de los padres que mantiene el referido cuidado, en lo tocante a la determinación de lugar de residencia. Así, el art. 49 de la ley $\mathrm{N}^{0} 16.618^{15}$, que regula la salida de menores desde el territorio nacional, dispone:

"si la tuición del hijo no ha sido confiada por el juez a alguno de sus padres ni a un tercero, aquél no podrá salir sin la autorización de ambos padres, o de aquel que lo hubiere reconocido, en su caso".

Asimismo, establece que en caso que el cuidado personal haya sido confiado a uno de los padres o a un tercero, el hijo no podrá salir del territorio nacional sin la autorización de aquel a quien se le hubiere otorgado la misma. Por último, también se requerirá la autorización del padre o madre no custodio, a favor de quien se haya regulado un régimen de relación directa y regular con el hijo ${ }^{16}$.

${ }^{14}$ Véase Monfort (n. 9), p. 128.

${ }^{15} \mathrm{DFL} \mathrm{N}^{\mathrm{O}} 1$, del Ministerio de Justicia, fija texto refundido, coordinado y sistematizado del Código Civil; de la ley $\mathrm{N}^{\mathrm{o}} 4.808$, sobre Registro Civil; de la ley $\mathrm{N}^{\mathrm{0}} 17.344$, que Autoriza Cambio de Nombres y Apellidos; de la ley No 16.618, Ley de Menores; de la ley $\mathrm{N}^{\circ} 14.908$, sobre Abandono de Familia y Pago de Pensiones Alimenticias y de la ley $\mathrm{N}^{\circ} 16.271$, de Impuesto a las Herencias, Asignaciones y Donaciones. Diario Oficial, 30 de mayo de 2000.

${ }^{16}$ El permiso deberá ser otorgado por escritura pública o por escritura privada autorizada por un notario, o en su defecto, por sentencia judicial dictada por el tribunal competente. $\mathrm{Y}$ 
En nuestra legislación, la autorización que debe otorgar el padre que no es titular del cuidado personal se configura de pleno derecho cuando se haya regulado un régimen de relación directa y regular a su favor, sin que se necesite declaración expresa de la autoridad judicial competente. Es decir, debe ser considerado como un derecho inherente al régimen de visitas o comunicacional -un derecho ne exeat contenido por el solo ministerio de la ley en el régimen (véase infra n. 29)- que se concede a favor de uno de los padres. Debe tenerse presente que, en caso que se acredite que dicha autorización no pudo otorgarse o que ha sido denegada sin motivo plausible por quien deba prestarla, podrá ser otorgada por el juez, considerando el beneficio que le pudiese reportar al hijo dicho viaje, y debiendo siempre señalarse por el tiempo que se concede dicha autorización ${ }^{17}$.

En el Derecho Doméstico, entonces, la cláusula ne exeat va asociada al régimen de relación directa y regular. Sin embargo, y en el ámbito de la Convención de la Haya, analizaremos cómo las facultades que posee quien tiene un régimen comunicacional regulado pueden situarlo más cerca de un régimen de cuidado personal compartido-y, si no, llevarlo a ejercer facultades que tradicionalmente se han considerado propias de lo que en la práctica estadounidense ha sido conocido como la joint legal custody o tuición legal, es decir, la posibilidad de dirigir e intervenir en las decisiones 114 relevantes en la vida del hijo.

\section{Corte Suprema de Estados Unidos: Аbbott v. Аbbott RELACIÓN DIRECTA Y REGULAR CON CUIDADO PERSONAL}

Esta sección describe nuevos avances en el Derecho Comparado, mirando, en especial, a Estados Unidos. La razón para escoger esta nación descansa en dos motivos principales;

- primero, porque se trata del país que más casos resuelve sobre secuestro internacional de niños año a año ${ }^{18}$.

no será necesario en caso que el menor salga del país en compañía de la persona o personas que deban prestarlo.

${ }^{17}$ Además, tal derecho ne exeat podrá ser modificado por una declaración judicial expresa, en cuanto se acredite que quien tiene un régimen de visitas regulado ha dejado de cumplirlo injustificadamente (art. 49 bis ley $\mathrm{N}^{\circ} 16.618$ ). Lo propio acontecerá cuando en contra de quien deba prestar dicha autorización se hubiesen decretado alguno de los apremios señalados en los arts. 14 y 16 de la ley $\mathrm{N}^{\circ} 14.908$, por no pago de pensiones de alimentos. En este caso no se requerirá la autorización debiendo tan sólo el juez autorizar la salida del país del hijo.

${ }^{18}$ Ericka Schnitzer-Reese, "International Child Abduction to Non-Hague Convention Countries: The need for and International Family Court", in Northwestern University Journal of International Human Rights, vol. 2, Chicago, april 2004, disponible en: http://www.law. northwestern.edu/journals/JIHR/v2/7, visitada el 18 de enero de 2011. 
- segundo, porque la (re) definición de su jurisprudencia se encuentra vinculada a casos en que los derechos de relación directa y personal se han establecido por tribunales chilenos.

Los avances jurisprudenciales que repasamos tienden, de forma casi unánime, a interpretar de manera amplia los derechos de visita establecidos en la Convención de la Haya. Así, la Corte Suprema de Estados Unidos, en línea con otras Cortes, ha resuelto la interpretación de los derechos de autorización para dejar el país como derechos de cuidado personal. Como sostendremos, dicha uniformidad es uno de los objetivos buscados por la Convención. Comprender esta evolución será importante para las conclusiones que se extraen a propósito de la deficiente práctica doméstica, más interesada, como mostraremos, en hacer uso de las facultades excepcionales que de mantenerse fiel a los principios de la Convención.

\section{1) La Convención de la Haya y el planteamiento del problema}

A medida que las comunicaciones y el traslado entre países se hicieron más fáciles, un mayor número de parejas comenzaron a viajar, contraer matrimonio y tener hijos en el extranjero. Se trata, qué duda cabe, de un proceso global; chilenos y chilenas establecen relaciones familiares con extranjeros, se avecinan en Chile o en otros países, desarrollan una vida familiar y, junto a ella, los problemas propios de la vida en común cuyo punto cúlmine es la separación y el divorcio. En el ámbito de "parejas plurinacionales" -concédasenos la expresión- el fin de la vida en común va de la mano con el retorno a los países de origen ${ }^{19}$. Como suele ocurrir durante estos procesos, niños, niñas y adolescentes, hijos de la familia cuya vida en común termina, son seriamente afectados, ya no sólo por las consecuencias psicológicas de la separación -cuyo análisis no es objeto de este trabajo- sino por la utilización de la que son objeto en las disputas entre adultos (o por el simple hecho de estar en el lugar inadecuado en el momento menos indicado).

Durante la etapa de elaboración de los trabajos iniciales, que concluirían con la elaboración de la Convención, se detectaron una serie de nuevos problemas globales que surgían a partir de esta nueva realidad, pero que carecían de respuestas consensuadas que les hicieran frente. Las dificultades identificadas, entonces, iban desde los problemas prácticos que entrababan la localización de los niños secuestrados, a la ausencia de colaboración efectiva de autoridades locales y extranjeras, todo ello en un contexto que

${ }^{19}$ Cuestión que no necesariamente es siempre así, ni quiere decir que la Convención no proceda, por ejemplo, para casos en que ambos padres son nacionales de un Estado, pero donde uno de ellos toma al hijo para llevarlo al extranjero. 
carecía de la logística requerida para resolver disputas internacionales ${ }^{20}$.

Como se aprecia, el problema a resolver entre las diferentes legislaciones nacionales involucradas no era uno en que sólo se decidirían derechos y obligaciones de los padres respecto de sus hijos, sino que, principalmente, uno en que debía idearse un mecanismo para decidir qué hacer con el niño que había sido trasladado fuera de su entorno familiar y social habitual de residencia ${ }^{21}$. Como indica Michael Freeman, la Convención, así, asume como principio fundante que "el rápido retorno del niño secuestrado a su país de residencia habitual se dirige siempre a satisfacer su interés superior" 22 . En efecto, y a diferencia de lo que ocurre en los procedimientos domésticos - prosigue el autor- el bienestar del niño no es la consideración primordial $^{23}$. Lo es, en cambio, el hecho de poder devolverlo al lugar de residencia habitual donde, se asume:

a) será más fácil que el caso de fondo (i.e. tuición, visitas, etc.) sea decidido con el máximo acceso posible a información relevante ${ }^{24}$

b) o que se respetarán los derechos ya decididos en la jurisdicción local (i.e. custodia compartida o visitas). Al mismo tiempo, en la medida que se impidan los secuestros

c) se desincentivará el uso de los mismos en el propio beneficio de los padres en disputa ${ }^{25}$.

116 Así lo declara en su preámbulo, por lo demás, la propia Convención de la Haya (n. 11): ella nace con el objetivo de proteger al niño en contra de su traslado o retención ilegítima.

Acreditado que un traslado o retención sea ilegítimo, la Convención busca que las cosas vuelvan a su estado anterior, asegurando, de esa forma, que los derechos y obligaciones sean establecidos sobre la base del ordenamiento jurídico del país de residencia habitual del niño en cuestión,

${ }^{20}$ Carol Bruch, "The Hague Child Abduction Convention: past, accomplishments, future challenges", in Sharon Detrick \& Paul VlaArdingerbroek (eds.), Globalization of Child Law: The role of the Hague Conventions, Hague, Martinus Nijhoff Publishers, 1999, p. 34.

${ }^{21}$ Elisa Pérez-Vera, "Informe explicativo de la Convención de la Haya de 1980 sobre Secuestro de Niños", in Hague Conference on Private International Law, 1982, p. 3, disponible en: http://www.hcch.net/index_en.php?act=publications.details\&pid=2779, visitada el 13 de enero de 2011.

${ }^{22}$ Michael Freeman, A commentary on the United Nations Convention on the Rights of the Child. Article 3: The Best Interest of the Child, Leiden, Martinus Nijhoff Publishers, 2007, p. 17.

${ }^{23}$ Op. cit., p. 17.

${ }^{24}$ BRuch (n. 20), p. 35. De hecho, el objetivo es que los casos de fondo no sean decididos en el país en el cual se encuentra secuestrado el niño, cuestión que permitirá que los Estados contratantes respeten sus decisiones de fondo. Blanca GómEZ, Aspectos civiles de la sustracción de internacional de menores: problemas de aplicación del Convenio de la Haya de 25 de octubre de 1980, Madrid, Dykinson, 2002, p. 86.

${ }^{25} \mathrm{BRUCH}$ (n. 20), p. 35. 
siempre cuando no haya alcanzado la edad de dieciséis años. ¿Cuándo se entiende, entonces, que hay un traslado o retención ilegítima -en términos de la Convención- de un hijo? Su art. $3^{\circ}$ dispone:

“[e]l traslado o la retención de un niño se considerará ilícito en los siguientes casos:

a) cuando tiene lugar en violación a un derecho de tuición asignado a una persona, una institución o cualquier otro organismo, en forma separada o conjunta, en virtud de la ley del Estado en el cual el niño tenía su residencia habitual inmediatamente antes de su traslado o retención; y

b) cuando dicho derecho ha sido efectivamente ejercido en forma separada o conjunta en el momento del traslado o retención, o lo hubiera sido si no hubieren ocurrido tales hechos.

El derecho de tuición mencionado en la cláusula a) anterior, podrá derivar en particular de una atribución de pleno derecho, de una resolución judicial o administrativa, o de un acuerdo en vigencia en virtud de la ley de ese Estado".

En consecuencia, el arreglo remedial que dispone la Convención, esto es, el retorno inmediato del niño secuestrado, opera sólo para el caso en que se infrinjan derechos de tuición (custodia o, para el caso chileno, cuidado personal) o cuando la realización de ese derecho se haya vuelto imposible, justamente, en virtud del secuestro. Desde luego, del hecho que los derechos de custodia sean los que provocan el retorno inmediato del menor, no se sigue que, para la Convención, los derechos de visita sean irrelevantes (sin perjuicio que contempla otro tipo de remedios, distinto del retorno inmediato, infra n. 28). En rigor, y apreciando sus objetivos ya identificados, aquélla aspira a que los derechos de visita decretados en el país de residencia habitual sean, también, respetados ${ }^{26}$; es decir, que el padre o la madre con derechos de visita en el país de residencia habitual, no se vea defraudada en el ejercicio de los mismos a raíz del secuestro ${ }^{27}$.

¿Cuál es el problema que ha causado la aplicación de la Convención y en el que queremos centrar nuestra atención? Como se advierte, bajo su tutela sólo los derechos de custodia provocan el retorno inmediato del niño (el arreglo remedial que dispone la misma). De ello, como acabamos de

${ }^{26}$ Michael Walshand \& Susan SAVARD, "International Child Abduction and the Hague Convention", in Barry Law Review, Orlando, vol. 6, 2006, p. 30.

${ }^{27}$ Como señalaremos más adelante, este propósito de la Convención ha sido clave para la relectura jurisprudencial que se ha hecho de ciertos derechos de visita -a saber, aquéllos que contienen cláusulas ne exeat. 
decir, no se sigue que los derechos de visita sean irrelevantes, pues uno de sus objetivos es que, con el retorno, justamente, se respeten esos derechos decretados en el país de residencia habitual. Sin embargo, ocurre que, bajo la misma, si un padre o madre es titular de derechos de visita no puede reclamar el retorno inmediato de su hijo o hija secuestrada, aunque sí otras medidas $^{28}$. ¿Nunca? La respuesta es no. Hay que distinguir, pues, como diremos, ciertos derechos de visita pueden leerse, a la luz de la Convención, como derechos de custodia, provocando el retorno inmediato del menor.

El texto de la Convención, amplio y vago, ha sido de poca ayuda a la hora de delimitar el rango de situaciones que cobija la hipótesis de custodia. De acuerdo con su art. $5^{\circ}$ :

“a) el 'derecho de tuición' comprenderá el derecho relativo a los cuidados de la persona del niño y, en particular, el derecho a determinar su lugar de residencia;

b) el 'derecho de visita' comprenderá el derecho de llevar al niño por un período limitado a un lugar que no sea su lugar de residencia habitual".

Por lo mismo, parte importante de la discusión se ha centrado en determinar cuál es la forma en que los derechos de visita (acceso, contacto o, para Chile, relación directa y regular) son recogidos por la Convención y si acaso, como ha ocurrido desde hace un tiempo, ciertas formas de regímenes de relación directa y regular pueden leerse, a su abrigo, como derechos de custodia. Si es del caso que ciertas formas de regímenes de visita pueden considerarse como derechos de custodia a su amparo, entonces para esas situaciones también deberá decretarse el retorno inmediato del niño. En efecto $-\mathrm{y}$ con esto adelantamos el análisis jurisprudencial que sigue- si

${ }^{28}$ Por ejemplo, el padre o madre que ha secuestrado o removido al hijo violando derechos de visita, debe permitir y, en ciertos casos, financiar visitas periódicas del padre o madre que carece de derechos de custodia, y que, insistimos, bajo la Convención no puede solicitar el retorno inmediato. Todo esto, en virtud de su art. 21: "Una solicitud dirigida a la Autoridad Central de un Estado Contratante podrá ser presentada para que se organice o proteja el ejercicio efectivo del derecho de visita, conforme a la misma modalidad que una solicitud para el regreso del niño.

Las Autoridades Centrales estarán ligadas por las obligaciones de cooperación estipuladas en el Artículo 7 para asegurar el ejercicio pacífico del derecho de visita y el cumplimiento de cualquier condición a la cual esté sujeta el ejercicio de dicho derecho. Asimismo, éstas tomarán medidas para eliminar, en lo posible, los obstáculos que se opongan al ejercicio de tal derecho.

Las Autoridades Centrales, ya sea directamente o a través de intermediarios, podrán entablar o favorecer el inicio de un procedimiento legal con miras a organizar o proteger el derecho de visita y las condiciones a las cuales pueda estar sujeto el ejercicio de ese derecho". 
el padre que no tiene el cuidado personal (custodia) sobre su hijo posee, en cambio, derechos de visita acompañados de la facultad para autorizar que éste deje el país (o para negar el permiso, si así lo estima), entonces, el quebrantamiento de los derechos de visita, así configurados, provocan el retorno inmediato del niño.

Éste es el caso que analizamos a continuación y que, en el marco de nuestra legislación doméstica, cobra especial relevancia: si el derecho del cual goza el padre que no tiene cuidado personal para autorizar que su hijo abandone el país opera de pleno derecho, según dispone el art. 49 de la Ley de Menores (véase sección II. 2), entonces, en Chile los regímenes de relación directa y regular (visitas) contienen siempre-en virtud del mandato legal- una cláusula ne exeaty, a salvaguardia de la Convención, constituyen derechos de custodia (o de tuición legal, de acuerdo con la práctica estadounidense), en términos que quien debe otorgar dicha autorización, no queda excluido de intervenir en las decisiones relevantes de la vida del hijo.

\section{2) El contexto judicial antes de Abbott v. Abbott: el sentido de las cláusulas ne exeat}

Una cláusula ne exeat, es aquélla que prohíbe a la persona a la cual se dirige dejar el país, el Estado o la jurisdicción de lo tribunales ${ }^{29}$. En el caso del Derecho de Familia, y para el tipo de situaciones que acá revisamos, estas cláusulas poseen, también, una cara positiva: con ellas, según dispone el art. 49 de la Ley de Menores, se faculta a uno de los padres, para autorizar, si así lo decide, el traslado de su hijo al extranjero. Respecto de parejas separadas, entonces, es posible que uno de los padres sea titular sólo de derechos de visita, pero que, en virtud de la disposición legal antes identificada, sume, a esos derechos, una cláusula ne exeat. Dichas cláusulas, no está demás recordarlo, pueden establecerse por orden judicial, administrativa u operar de pleno derecho, esto es, por efecto de la ley.

Previo a Abbott, las Cortes de Estados Unidos se encontraban divididas respecto al alcance de dichas cláusulas y su lectura bajo la Convención. Por una parte, algunas sostuvieron que los derechos de visita a los cuales se suma una cláusula ne exeat son sólo derechos de visita y no gatillan, por ende, la devolución inmediata del niño o niña. Otras, junto a la Corte Suprema, en cambio -y en línea, como indicaremos, con la tendencia comparadasostuvieron que bajo la Convención los derechos de visita acompañados de cláusulas ne exeat configuran derechos de custodia, toda vez que autorizan

${ }^{29}$ Arpita GuPTE, "International Law: Rights of access with ne exeat clause do not create rights of custody under Hague Convention-Abbott v. Abbott, 542 F.3d 1081 (5 $5^{\text {th }}$ Cir. 2008)", in Suffolk Transnational Law Revier, vol. 33, No 1, Boston, 2010. 
al padre titular -según el lenguaje del referido instrumento- "a determinar el lugar de residencia" del niño. Repasemos su art. $5^{\circ}$ letra a), que define los derechos de custodia:

"el 'derecho de tuición' comprenderá el derecho relativo a los cuidados de la persona del niño y, en particular, el derecho a determinar su lugar de residencia".

\section{A. Derechos ne exeat como derechos de visita}

Para el primer grupo de casos, Croll v. Croll marca la pauta ${ }^{30}$. En Croll, la madre y su hija vivían en Hong Kong. Mientras la custodia había sido otorgada a la madre, el padre gozaba de derechos "razonables de visita". La madre llevó a su hija hacia Estados Unidos donde, una vez establecida, comenzó procedimientos judiciales para solicitar su custodia -se entiende, ahora, en dicho país. El padre, por su parte, presentó una demanda al amparo de la Convención, solicitando el retorno de la niña.

La Corte de Apelaciones del Segundo Circuito identificó rápidamente el asunto a debatir: ¿̇los derechos de visita a los que se suma una cláusula ne exeat, constituyen derechos de custodia al amparo de la Convención? Respondió de forma negativa a la pregunta. Para la Corte, los derechos de custodia

"conllevan el deber y facultad primaria de elegir y proporcionar sustento, alimento, vestimenta, guía espiritual y moral, atención médica, educación, etc." 31 .

Como Jane Jackson ha notado, para la Corte los derechos de custodia, no definidos en la Convención, configuran un derecho de cuidado activo de parte de su titular, esto es, un cuidado que se dota de sustancia por acciones y decisiones del padre o madre titular de los derechos de custodia, y no, en cambio, por una simple oposición ${ }^{32}$.

Así, la Corte, afirma:

“el derecho especificado [en el art. $5^{\circ}$ a)] es el 'derecho a determinar'el lugar de residencia habitual de un niño, cuestión que implica, por lo tanto, un poder activo para elegir (y cambiar) el lugar de residencia, a discreción, como parte de una decisión parental y personal”33.

${ }^{30}$ Croll v. Croll, F.3d, 133, 2d Cir., 2000.

${ }^{31}$ Croll, p. 50 (las traducciones que siguen nos pertenecen).

${ }^{32}$ Jane JACKSON, "Interpreting ne exeat rights as rights of custody: the United States supreme Court's chance to advance the purposes of the Hague Convention on International Child Abduction", in Tulane Law Review, vol. 84, New Orleans, November 2009, p. 202.

${ }^{33}$ Croll (n. 30), p. 139 (el énfasis es de la Corte). 
¿Por qué los derechos de visita del padre, acompañados por una cláusula ne exeat no satisficieron el estándar de la Corte? Porque para la Corte, las cláusulas ne exeat conceden a su titular sólo un derecho de veto (en muchos casos, parcial) que no se condice con las facultades activas a que hace referencia un derecho de custodia:

"la cláusula ne exeat [de la cual goza el padre] limita las facultades de custodia de la madre para llevar fuera del país a C., pero no el poder de ésta para determinar el lugar de residencia" 34 .

Por ello es que la

“orden que determina la custodia de C. le concede al padre un simple poder de veto -sólo referido a la posibilidad que su hija deje el país- pero no le permite tomar cualquier otro tipo de decisión relativa a su custodia, incluido el 'lugar de residencia' de C. dentro de Hong Kong" 35 .

Pero las Cortes de Estados Unidos también han estado dispuestas a sostener la tesis contraria: que las cláusulas ne exeat acompañando derechos de visita configuran, al amparo de la Convención, derechos de custodia.

B. Derechos ne exeat como derechos de custodia

En Furnes v. Reeves ${ }^{36}$, por su parte, la Corte de Apelaciones de $11^{\circ}$ Circuito estuvo por sostener la tesis de que los derechos ne exeat, considerados junto con derechos de visita, configuran derechos de custodia al amparo de la Convención. Luego de una serie de decisiones judiciales sobre custodia y derechos de visita, definidos en Noruega, los padres de una niña de cinco años acordaron "responsabilidad parental compartida," no obstante la menor viviría con su madre y se había establecido un amplio régimen de visitas a favor del padre. Bajo la ley noruega, dicho régimen faculta al padre para "adoptar decisiones por el niño en asuntos personales" ${ }^{37}$. Sin embargo, cuando uno de los padres vive con el hijo, las facultades del otro padre se estrechan; en efecto, pese al régimen de "responsabilidad parental compartida", el padre que no vive con él

\footnotetext{
${ }^{34}$ Croll (n. 30), pp. 139-140.

${ }^{35}$ Ibid.

${ }^{36}$ Furnes $v$. Reeves, 362, F.3d, 702, $11^{\text {th }}$ Cir., 2004 (las traducciones que siguen nos pertenecen).

${ }^{37}$ Op. cit., pp. 706-707.
} 
"no puede objetar las decisiones que el padre que vive con el hijo [en este caso, la madre] adopte sobre aspectos importantes del cuidado del niño"38.

Por último, aunque la madre que vive con la menor puede determinar soberanamente dónde vivirá con ella dentro de Noruega,

"la Ley de Menores faculta al padre bajo régimen de responsabilidad parental compartida... con la autoridad para decidir acaso el niño puede abandonar el país... debiendo ambos padres consentir para que el niño pueda trasladarse" 39 .

Sin dicho consentimiento, la madre tomó a su hija desde Noruega a Estados Unidos, razón por la cual el padre presentó una solicitud de retorno al amparo de la Convención, que había sido rechazada por el tribunal de distrito, pues, sostuvo, "el padre sólo ejercía derechos de visita acompañados de una cláusula ne exeat... y no derechos de custodia" ${ }^{40}$. En apelación, la Corte advierte el asunto específico sobre el cual debe pronunciarse:

“acaso los derechos del padre sobre su hija bajo la ley noruega son del tipo de derechos que, en términos de la Convención, lo faculten para exigir el retorno inmediato de la niña" ${ }^{41}$.

Nos centramos en la forma en que la Corte reconstruye los derechos de custodia al amparo de la Convención, en especial tomando en cuenta la forma en que se hace cargo de los argumentos de la Corte en Croll ${ }^{42}$. En

${ }^{38}$ Furnes (n. 36), p. 707.

${ }^{39}$ Op. cit., pp. 707-708.

${ }^{40}$ Op. cit., p. 709.

${ }^{41}$ Op. cit., p. 710.

${ }^{42}$ La Corte comienza analizando los derechos que surgen para el padre a partir del régimen de "responsabilidad parental compartida". A su amparo, afirma, el padre puede "adoptar decisiones relativas los asuntos personales de la niña," no obstante -como hemos dicho- no se encontraba facultado para objetar las decisiones de la madre relativas a "aspectos importantes del cuidado de ésta." Luego sostiene: bajo este esquema de derechos-obligaciones se configura un régimen de custodia compartida; en efecto -según argumenta- si el padre que no vive con su hija "puede adoptar decisiones relativas a asuntos personales" de ésta e, incluso, "decisiones relativas a su cuidado"-aun cuando sin entrar a definir aspectos importantes de ese cuidado, cuestión que corresponde a la madre que vive con ella, entonces hay decisiones que se adoptan en asuntos relativos al cuidado del niño, según define la Convención en su art. 5. Furnes (n. 36), pp. 712-14.

Es posible que la Corte pudiera haber adjudicado el caso a favor del padre basado en este puro análisis. Sin embargo, el mismo tribunal insiste en afirmar que su decisión de 
Furnes, el tribunal se pregunta, ċacaso los derechos ne exeat pueden entenderse -al amparo de la Convención- como atribuciones que permitan a su titular "determinar el lugar de residencia" del niño? Y responde afirmativamente. Para ello, nota que la cláusula ne exeat configura un derecho-deber de custodia compartido para los padres. Así, la madre, que tiene derechos de custodia sobre su hija, puede tomar importantes decisiones relativas a su cuidado, pero, llegado el momento de definir si ella abandona el país, debe, necesariamente, contar con el consentimiento del padre (titular del derecho ne exeat $)^{43}$. Como el padre tiene que consentir -razona la Corte"tiene el derecho conjunto para decidir, junto a la madre, acaso su hija vivirá dentro o fuera de Noruega" 44 .

Además -y encarando derechamente los argumentos de la Corte Croll- afirma que los derechos ne exeat son más que un mero veto, pues, ejerciendo ese derecho, no sólo puede negar (veto) sino que, además -si la madre respeta los derechos ne exeat y solicita su autorización, como corresponde- "consentir el traslado de la niña sobre la base de cualquiera de las condiciones que escoja"45. Y aun cuando se lo considerara un simple veto, al final del día, es la decisión del titular de los derechos ne exeat la que determina el lugar de residencia del menor; en palabras de la Corte y al amparo de la Convención, sin duda "una decisión relativa a los cuidados de la persona del niño (art. 5 de la Convención)" ${ }^{\prime 6}$.

\section{El papel de la Corte Suprema}

Las decisiones recién aludidas, Croll y Furnes, son sólo indicativas de la división que existía entre las Cortes de los diferentes circuitos. Parte importante de las críticas que se dirigieron en contra de los argumentos en Croll, y en los casos que lo siguieron ${ }^{47}$, se referían a la escasa atención que se prestaba a los objetivos de la Convención, así como a la forma en que ésas decisiones la transformaban en letra muerta. Por una parte, se afirmó, como hemos dicho, que la Convención busca reestablecer el status quo, es decir, busca hacer que las cosas se retrotraigan al estado anterior al secuestro para asegurar el respeto de las decisiones jurisdiccionales de los países

reconocer los "derechos de custodia del padre no se basan únicamente" en los argumentos antes mencionados, reparando especialmente en el derecho ne exeat de aquél para definir el lugar de residencia de su hija (Furnes (n. 36), p. 714). Por ello decimos que nos centramos en la decisión de la Corte en torno a los derechos de visitas con cláusulas ne exeat.

${ }^{43}$ Op. cit. (n. 36), p. 715.

${ }^{44}$ Ibid.

${ }^{45}$ Ibid.

${ }^{46}$ Op. cit., pp. 716, 719-720.

${ }^{47}$ Fawcett v. McRoberts, 326, F.3d, 491, $9^{\text {th }}$ Cir., 2001; González v. Gutiérrez, 311, F.3d, 942, $9^{\text {th }}$ Cir., 2002. 
miembros. Por lo mismo, los términos de su texto deben interpretarse a la luz de dichos objetivos, y no sobre la base de consideraciones aisladas ${ }^{48}$ -como la Corte Croll, cuya definición de derechos de custodia comienza con referencias a diccionarios legales.

Por otra, se cuestionó duramente los efectos que las decisiones podrían causar en la aplicación práctica de la Convención. Finalmente, el padre o la madre secuestradora se terminaría beneficiando de su propia acción en incumplimiento de las decisiones judiciales o de las disposiciones legales (o de ambas), transformando la Convención y los derechos que ella establece en una ilusión ${ }^{49}$.

Por lo mismo, parte importante de la discusión se planteó en torno al reclamo por una decisión de la Corte Suprema. Como se conoce, el sistema estadounidense es especialmente sensible a la uniformidad de la interpretación judicial, misma que asume la Corte Suprema a través de la institución del certiorari. El certiorari-en latín "para estar más informado"en términos técnicos
"una orden judicial por medio de la cual una corte de apelaciones, a discreción, ordena a una corte inferior enviar todos los antecedentes de un caso para su revisión" 50 .

El mismo opera a nivel de Corte Suprema que, sobre la base de un sistema respetuoso del precedente, uniforma "hacia abajo" las interpretaciones judiciales. La uniformidad de la interpretación, además, es especialmente sensible en el caso de la Convención. En efecto, a los reclamos anteriores debe agregarse que en el Derecho Comparado las cláusulas ne exeat son concebidas como derechos de custodia al amparo de la Convención ${ }^{51}$ -cuestión que generaba un nivel de falta de uniformidad- que se sumaba a la división interna de las Cortes de los diferentes circuitos. La Corte $\mathrm{Su}$ prema se había negado a revisar estas interpretaciones hasta que la Corte del Quinto Circuito decidió Abbott v. Abbott ${ }^{52}$, descansando fuertemente en Croll.

${ }^{48}$ Kathleen O' Connor, "What gives you the right?! Ne exeat rights should constitute rights of custody after Furnes v. Reeves”, in Penn State International Law Review, vol. 24, Pennsylvania, 2005, pp. 469-470; JACKSON (n. 32), pp. 213-215.

${ }^{49}$ O' Connor (n. 48), p. 470; JAckson (n. 32), pp. 214-215; Sara Bass, "Ne exeat clauses proven ineffective: how the Hague Convention renders access rights illusory", in North Carolina Journal of International Law and Commercial Regulation, vol. 29, Chapel Hill, 2004.

${ }^{50}$ Black's Law Dictionary, St. Paul, Thomson West, 2006 p. 93.

${ }^{51}$ Walshand \& Savard (n. 26), p. 37; Jackson (n. 32), pp. 208-212; O' Connor (n. 48), pp. 465-468.

${ }^{52}$ Abbott (n. 5). 


\section{3) Abbott v. Abbott}

El pronunciamiento de la Corte Suprema de Estados Unidos se origina a consecuencia de una demanda interpuesta por el señor Abbott (ciudadano británico) ante la Corte Federal de Distrito, mediante la cual solicita -conforme a la Convención- el regreso inmediato de su hijo A.J.A. a Chile. Para ello, argumentó que ha sido traslado ilícitamente por su madre (ciudadana estadounidense) desde Chile -lugar que constituía su residencia habitual-a Texas, Estados Unidos.

Separada la pareja, los tribunales de familia chilenos habían concedido a la madre el cuidado personal, habiéndose regulado, asimismo, un régimen de relación directa y regular a favor del padre (fin de semana por medio y vacaciones durante todo el mes de febrero de cada año). En agosto de 2005, la madre trasladó a su hijo fuera de Chile. Lo hizo sin la autorización del padre ni de un tribunal. Lo anterior llevó al padre (el señor Abbott) a demandar ante la Corte Federal del Distrito el inmediato regreso del niño a Chile, en aplicación del convenio. La Corte Federal negó lugar a la solicitud bajo el argumento que el derecho ne exeat del padre no era constitutivo de un derecho de custodia, de manera tal que el regreso inmediato no se encontraba autorizado como arreglo remedial al amparo de la Convención. El tribunal del $5^{\circ}$ Distrito, así, se cuadraba con la Corte de Croll, caso en que descansó.

La Corte Suprema, sin embargo, revocó la decisión de la Corte Federal, ordenando el regreso del hijo a Chile. La Corte Suprema señala que la aplicación del Convenio radica en que se han verificado los siguientes requisitos, a saber: que A.J.A. es un niño menor de dieciséis años; que residía junto a su madre de forma habitual en Chile, previo a ser trasladado a Texas, Estado Unidos; y que tanto Chile como Estados Unidos son Estados contratantes.

La Corte en su sentencia busca determinar si ha existido un traslado ilícito, entendiéndose que existe cuando ha habido una violación del derecho de tuición en virtud de la ley del Estado en el cual el niño tenía su residencia habitual inmediatamente antes de su traslado o retención, es decir -en este caso-, de acuerdo con la legislación chilena. Ya hemos dicho que la Convención define el derecho de tuición, de forma vaga e imprecisa, como el derecho relativo a los cuidados de la persona del menor y, en particular, el derecho a determinar su lugar de residencia. La Corte Suprema -interpretando la legislación chilena aplicable- establece en la presente sentencia en comento que efectivamente A.J.A. fue traslado en forma ilícita desde Chile a Estados Unidos, toda vez que fue violado el derecho de tuición del padre. ¿Cómo llega entonces a esta conclusión la Corte, a pesar de que la madre era quien, de acuerdo con nuestra legislación, tenía el cuidado personal 
(o tuición) sobre su hijo, todo en virtud de una resolución judicial de los juzgados de familia chilenos?

La Corte funda dicha decisión a partir del contenido del derecho que consagra el art. 49 de la ley $\mathrm{N}^{\mathrm{o}} 16.618$, a cualquier padre que sea titular de un régimen de relación directa y regular, el que, como vimos antes (II. 2), consagra un derecho ne exeat. En esta norma se establece

“confiada por el juez la tuición a uno de los padres o a un tercero, el hijo no podrá salir sino con la autorización de aquel a quien se hubiere confiado, pero establece además que regulado el derecho a que se refiere el artículo 229 del Código Civil por sentencia judicial o avenimiento aprobado por el tribunal, se requerirá también la autorización del padre o madre a cuyo favor se estableció”.

En este sentido la Corte concluye que bajo la disposición anterior "el Sr. Abbott tiene un derecho conjunto de determinar el país de residencia de su hijo" ${ }_{53}$. Por lo mismo, insiste el tribunal, la norma citada también le otorga "derechos en lo concerniente al cuidado personal de niño", en consideración a que elegir el país de residencia de A.J.A. puede determinar la forma de sus primeros años y de sus años adolescentes, así como su 126 lengua, identidad, cultura y tradiciones. Así, concluye que en virtud del derecho ne exeat, que consiste en la facultad de autorizar que el otro padre pueda trasladar a un niño, se deriva un derecho de tuición o custodia al amparo de la Convención.

Señala, asimismo, que el hecho de que la figura del ne exeat no encaje dentro de las nociones de custodia física no viene al caso, pues la definición del Convenio de "derecho de custodia" es la que manda ${ }^{54}$. Es decir, la Corte clasifica el derecho ne exeat del señor Abbott como uno de custodia y no de visitas o de acceso, enmarcándolo en la hipótesis del art. 5 a) de la Convención. De paso, entiende que el derecho ne exeat, de autorizar o no la salida del niño y de determinar el lugar de residencia del mismo, configura un derecho conjunto de tuición, es decir, del padre y madre relativo a los cuidados del niño. Establece así la Corte:

"se desprende que la protección que otorga la Convención al derecho de custodia de un padre, le da el derecho de determinar el lugar de residencia del niño".

${ }^{53}$ Abbott (n. 5), p. 12 (las traducciones que siguen son nuestras).

${ }^{54}$ Op. cit., p. 3. 
Finalmente, concluye:

"el derecho conjunto del Sr. Abbott para determinar el país de residencia de A.J.A. también le confiere derecho sobre el cuidado de la persona del niño" ${ }^{\text {55 }}$.

\section{PRÁCTICA DOMÉSTICA: ¿PRIVILEGIANDIO LAS EXCEPCIONES?}

Como hemos visto, de acuerdo con la Convención, para que el retorno inmediato del niño o niña sea ordenado, se requeire demostrar, entonces:

a) que se ha producido un traslado ilícito, esto es, en violación de derechos de custodia o cuidado personal en los términos de la Convención;

b) tomando al niño o niña desde su país de residencia habitual. Sin embargo, la misma Convención establece hipótesis de excepción.

\section{1) La excepción del art. 13 letra b) de la Convención}

De acuerdo con el art. 13 letra b) de la Convención:

"[n]o obstante las disposiciones del Artículo precedente, la autoridad judicial o administrativa del Estado requerido no estará obligada a ordenar el regreso del niño en caso de que la persona, la institución, o el organismo que se opone a su regreso establece que:

b) existe un grave riesgo de que el regreso del niño lo exponga a un peligro físico o sicológico, o de otro modo lo ponga en una situación intolerable. La autoridad judicial o administrativa podrá también negarse a ordenar el regreso del niño, si comprueba que él se opone a su regreso, y ha llegado a una edad y a un grado de madurez en las que su opinión merece tenerse en cuenta”.

Si se aprecia con cuidado, la hipótesis de excepción se construye, de nuevo, sobre la base del respeto del interés superior del menor. Tan así es esto que el niño o la niña que "ha llegado a una edad y a un grado de madurez en las que su opinión merece tenerse en cuenta", puede oponerse. Reiterando lo que señaláramos antes, sin embargo, dicho interés se satisface, en principio, con el retorno del niño o niña a su país de residencia

${ }^{55}$ Abbott (n. 5), p. 13. 
habitual ${ }^{56}$. Por lo mismo, las hipótesis de excepción deben interpretarse restrictivamente, esto es, los jueces y juezas deben desplegar un especial nivel de escrutinio de las razones que invoca un padre o madre secuestrador para intentar demostrar que existe "un peligro físico o sicológico, o de otro modo lo ponga en una situación intolerable" al menor en su país de residencia habitual.

En efecto, la historia de la redacción de la Convención sugiere lo que acá venimos señalando: que las excepciones debían establecerse y posteriormente interpretarse en términos restringidos, pues, de otra forma, se terminaría subvirtiendo el objetivo primario buscado por el establecimiento de la Convención. Así, en el "Informe explicativo..." de Elisa Pérez Vera, repasando el establecimiento de este instrumento, se señala:

"parece necesario subrayar que las excepciones, de los tres tipos examinados, al retorno del menor deben ser aplicadas como tales. Esto implica ante todo que deben ser interpretadas de forma restrictiva si se quiere evitar que el Convenio se convierta en papel mojado. En efecto, el Convenio descansa en su totalidad en el rechazo unánime del fenómeno de los traslados ilícitos de menores y en la convicción de que el mejor método de combatirlos, a escala internacional, consiste en no reconocerles consecuencias jurídicas" ${ }^{57}$.

La jurisprudencia comparada así lo ha entendido también. En Estados Unidos, por ejemplo, las hipótesis de grave riesgo que pueden exponer al niño a un daño físico o sicológico, se deben aplicar para casos en que el retorno lo coloque "bajo peligro inminente de circunstancias tales como guerra, hambre o enfermedad," o para casos en que el país de residencia habitual, por cualquier razón, "sea incapaz de proveer protección para el niño para casos serios de abuso o descuido" 58 . Así lo sostuvo la Corte de Apelaciones del $6^{\circ}$ Circuito de Estados Unidos en Friedrich v. Friedrich, en una fórmula que se ha ratificado con el tiempo ${ }^{59}$.

${ }^{56}$ Freeman (n. 22), p. 17. Al respecto, también, Caroline LeGette, "International Child Abduction and the Hague Convention: emerging practice and interpretation of the discretionary exception", in Texas International Law Journal, Texas, 1990, p. 294.

${ }^{57}$ Pérez Vera (n. 21), p. 8. En similar sentido Walshand \& Savard (n. 26), p. 38.

${ }^{58}$ Walshand \& SaVArd (n. 26), p. 41.

${ }^{59}$ Corte de Apelaciones del $6^{\text {o }}$ Circuito, Estados Unidos, 78, F.3d, 1060, 1996. "[W] e believe that a grave risk of harm for the purposes of the Convention can exist in only two situations. First, there is a grave risk of harm when return of the child puts the child in imminent danger prior to the resolution of the custody dispute -e.g., returning the child to a zone of war, famine, or disease. Second, there is a grave risk of harm in cases of serious abuse or neglect, or extraordinary emotional dependence, when the court in the country of habitual residence, for whatever reason, may be incapable or unwilling to give the child 
En Canadá, por su parte, se ha insistido en que la hipótesis de excepción que establece el art. $13 \mathrm{~b}$ ) debe entenderse excluyendo los efectos sicológicos propios del retorno del niño o niña. Así, en Thompson $v$. Thompson, la Corte Suprema de Canadá señaló:

"si bien es cierto que el niño sufrirá algún daño psicológico por el hecho de ser separado del cuidado de su madre para ser puesto al cuidado de su padre [que, en el caso, solicitaba su retorno], no se trata de un daño severo en los términos en que lo demanda la Convención. El daño físico o psicológico a que se refiere el art. 13 letra b) de la Convención debe entenderse que opera como excepción cuando se transforma en una situación intolerable. Es posible que el hecho mismo del retorno del niño hacia su padre, o el hecho de ser separado de quien actualmente cuida de él [su madre], cause en el niño algún daño; pero serán extremadamente extraños los casos en que el hecho que un niño esté ya asentado en el lugar del secuestrador constituya el tipo de riesgo que permite no decretar su retorno" 60 .

adequate protection". El test propuesto se ha consolidado con el tiempo, no obstante su apreciación práctica se ha sido relajando, convirtiéndola en objeto de varias críticas. Por ejemplo, en algunas decisiones se ha entendido que existen "zonas de guerra" en lugares de elevada inestabilidad política. Véase Galit Moskowitz, "The Hague Convention on International Child Abduction and the Grave Risk of Harm Exception. Recent decisions and their implications on children from nations in political turmoil", in Family Court Review, vol. 41, New York, 2003, pp. 588-590 (la autora enfatiza el peligro que se corre con una interpretación demasiado extensa de las cláusulas de excepción; hoy -afirma- dado que el terrorismo se encuentra ampliamente extendido en el mundo, es posible que uno siempre pueda construir una hipótesis de riesgo grave para el niño o niña).

${ }^{60}$ Corte Suprema de Canadá, Thompson v. Thompson, 3, S.C.R. 551, 1994. También en Estados Unidos véase Walshand \& SAvard (n. 26), p. 41. Audiencia Provincial de Barcelona, juicio No 338/08 JUR 2009/394078 (2009). En Friedrich (n. 59), la Corte afirmó que no se le debe permitir al padre secuestrador alegar que el niño ya se encuentra acostumbrado a un nuevo lugar ("A removing parent must not be allowed to abduct a child and then--when brought to court--complain that the child has grown used to the surroundings to which they were abducted. Under the logic of the Convention, it is the abduction that causes the pangs of subsequent return. The disruption of the usual sense of attachment that arises during most long stays in a single place with a single parent should not be a 'grave' risk of harm for the purposes of the Convention”). Lo mismo en Caroline LeGette quien, además, nota que el lenguaje de la Convención se refiere al riesgo de daño que se produce en el país de residencia habitual por el (en virtud del) retorno. LeGetTe (n. 56), pp. 297-298, 300-301. En España se ha fallado rechazando el retorno del niño por el sólo hecho que éste ya ha comenzado a desarrollar una suerte de nueva vida en el lugar del padre o madre secuestradora. Así, la Audiencia Provincial de Sevilla ha rechazado el retorno de un menor a Chile porque éste "se encuentra plenamente integrado en nuestro país (está escolarizada en el colegio... donde asiste regularmente a clases, está muy bien integrada con sus compañeros y tiene 
De otra forma, es decir, si cualquier tipo de efecto sicológico va a impedir que se decrete el retorno inmediato del niño a su país de residencia habitual, no sólo se frustrarán los objetivos de la Convención; además, el padre o la madre secuestradora van a verse favorecidos del propio acto de secuestro ${ }^{61}$. Por ello es que el tipo de evidencia que debe allegarse para provocar los efectos de la excepción debe ser concluyente respecto a que se está en frente de un riesgo grave e inminnente, no siendo suficiente las simples conjeturas ni el análisis del tribunal sobre cuál es el lugar donde el niño estará más feliz ${ }^{62}$. Es por lo anterior que -como afirma Michael Freeman- debe "existir evidencia clara y convincente sobre el grave riesgo de daño o circunstancias intolerables que deben ser substanciales y no sólo triviales" ${ }^{\prime 3}$. Los episodios pasados de violencia familiar, así como las posibilidades ciertas de violencia futura en contra del niño, constituyen evidencia suficiente para no decretar su retorno ${ }^{64}$. Pero la incertidumbre

un rendimiento escolar normal para su edad), y en el informe del equipo psicosocial de los Juzgados de Familia se concluye afirmando que la menor se encuentra debidamente atendida e integrada en su medio...”. Audiencia Provincial de Sevilla, Juicio No 36/08 JUR 2009/314040 (2009).

${ }^{61}$ Lo anterior fue advertido por la Corte Superior de California en el caso Navarro v. Bullock. En Navarro, la Corte advirtió que, permitir configurar la excepción del art. 13 130 letra b) sobre la base del daño psicológico propio de la separación del niño o niña con su padre o madre secuestradora, sería equivalente a permitirle al padre o madre secuestradora utilizar el riesgo de daño que ella misma ha creado en su favor ("The fact is, that the children have already been exposed to, and have suffered psychological harm due to their wrongful retention"). Citado en LeGetTe (n. 56), pp. 299-300.

${ }^{62}$ Esta conclusión es posible si se atiende a que el objetivo de la Convención es el de determinar cuestiones de jurisdicción y no, en cambio, de abrir el campo a la realización de análisis comparativos sobre cuál país es más seguro, adecuado, etc., para el niño o niña. Moskowitz (n. 59), p. 590. Cabe tener presente que, como se ha destacado, parte importante de las críticas a la forma amplia en que se han leído las cláusulas de excepción, radica en el campo que éstas abren para que los jueces puedan favorecer los estilos de vida y cultura de sus propias comunidades, al evaluar otras (por ejemplo, para determinar acaso formas de vida en un determinado país representan un "riesgo grave" para el niño o niña). Ejemplos de lo anterior en Theresa SpInillo, "The Hague Convention on the Civil Aspects of International Child Abduction: An analysis of the grave risk harm defense", in New York International Law Review, vol. 14, New York, 2001, pp. 140-146.

${ }^{63}$ Freeman (n. 22), p. 18.

${ }^{64}$ Es posible no proceder a ordenar el retorno, aun cuando la violencia no se dirija en contra del niño, pero cuando existan razones suficientes ("evidencia seria más que sólo conjeturas”) que hagan presumir que la medida podría terminar colocándolo bajo serio riesgo de violencia. Corte de Apelaciones de Ontario, Pollastro v. Pollastro, 171, D.L.R. $4^{\text {th }} 32,1999$ ("There is also evidence that returning T. to California represents a grave risk of exposure to serious harm to him personally. The father's hostility, irresponsibility and irrational behaviour are ongoing. Although J. P. has not been overtly physically violent to his son, he has been violent and had temper outbursts when his wife has been with the child. On one occasion, for example, he threw hot coffee at her, narrowly missing their 7-day-old 
e inestabilidad propia que un menor puede sentir al cambiar de país, justamente cuando se ordena su retorno, no puede leerse de manera amplia como configurando una hipótesis de riesgo grave y cierto ${ }^{65}$.

Desde luego que, según dispone la parte final del art. 13 de la Convención, para los casos en que el hijo secuestrado posea la edad y madurez suficiente y se oponga al retorno, también podrá denegarse, pese a que concurran los demás elementos que lo hacen procedente. En este sentido, se ha señalado:

"cuando la Convención de la Haya se refiere a la edad y madurez del niño apropiada para que sus puntos de vista sean tomados en cuenta, no debe entenderse que lo hace para que la aproximación de los jueces se haga desde una perspectiva en que generalmente

son whom she was holding. T. is barely two years old. His safety is seriously at risk if he is forced to return to the very volatility which caused his mother to leave with him in the first place. He and his mother would be removed from the sanctuary of her family in Canada, and forced to return to California where the potential for violence is overwhelming. This exposes the child to the serious possibility of substantial psychological and/or physical harm and, in addition, creates a grave risk that he would be placed in an intolerable situation"). La excepción del art. 13 letra b), por tanto, también se ha aplicado cuando existen episodios de violencia no contra el niño, sino contra la madre o padre (más probablemente contra la madre). Sin embargo, se trata de situaciones muy puntuales y sólo frente a circunstancias muy graves de agresión -y que el menor ha presenciado. Sharon NeLSON, "Turning our backs on the children: implications of recent decisions regarding the Hague Convention on International Child Abduction", in University of Illinois Law Review, No 2, Champaign, 2001, pp. 679-680. En sentido similar, Melissa Wills afirma que la excepción del art. 13 b) debe leerse de forma amplia, permitiendo que sea utilizada para comprender los casos en que existen abusos o violencia entre las parejas. Este acercamiento más flexible a la excepción, permitirá -afirma- comprender un número importante de casos de secuestro en que la madre (la más de las veces) escapa, con su hijo, de daño físico y emocional. Melissa S. WILLS, "Interpreting the Hague Convention on International Child Abduction: why American courts need to reconcile the rights of non-custodial parents, the best interests of abducted children, and the underlying objectives of the Hague Convention", in Review of Litigation, vol. 25, Texas, 2006, pp. 425-427.

${ }^{65}$ WALShAND \& SAVARD (n. 26), p. 41. Sharon Nelson ha abogado por una interpretación más amplia de la cláusula del art. $13 \mathrm{~b}$ ), argumentando a favor de incorporar el daño sicológico producto de la separación. NELSON (n. 64), p. 680 and ss. Sin embargo, debe notarse que su reclamo se construye sobre la base de lo que en 2001 se había transformado en una tendencia de algunas Cortes de Estados Unidos: el further analysis test. De acuerdo con dicho estándar, algunas cortes tenían por acreditado el riesgo cierto de grave daño pero, aun así, ordenaban el retorno del niño o niña. ¿La razón? Los tribunales procedía a analizar acaso el país de residencia habitual contaba con herramientas, instituciones y procedimientos que pudieran hacer frente a los daños graves que el menor podría sufrir (i.e. abuso sexual, físico, etc.), en caso de decretarse su retorno. Cuando las Cortes acreditaban que dichos procedimientos, herramientas e instituciones existían, ordenaban el retorno de todas formas, pp. 678-680, 690. 
se mira la capacidad de los niños... basta con que al hacérsele la pregunta 'cte opones a regresar a tu casa?' el niño sea capaz de entregar una respuesta que no dependa en el puro instinto, sino en la capacidad de poder discernir las razones que le hacen tomar esa respuesta que el niño toma como su superior interés" ${ }^{\prime 6}$.

Sin embargo, de lo anterior no se sigue que cualquier opinión del niño o niña deba ser tomado en cuenta para configurar la hipótesis de excepción. En efecto, la opinión debe evaluarse, de nuevo, al amparo de los objetivos de la Convención ${ }^{67}$. Al mismo tiempo, un tribunal debe ser capaz de advertir las diferencias que existen entre los deseos del hijo de permanecer con su padre o madre que lo ha secuestrado, de las alegaciones que él mismo pueda esgrimir contra el retorno a su país de residencia habitual ${ }^{68}$; sólo estas últimas operan como criterio para denegar el retorno. Al mismo tiempo, deben idearse mecanismos que le permitan a un tribunal -con la ayuda técnica necesaria- poder determinar si la opinión del niño es, en verdad, la suya y que no obedece, en cambio, a las manipulaciones de las que puede haber sido objeto de parte de su padre o madre secuestrador ${ }^{69}$.

Finalmente, el recurso al art. 13 letra b) no puede servir de excusa para revisar los méritos de la decisión de custodia o derechos de visita declara132 dos por la jurisdicción del país de residencia habitual. En otras palabras, la excepción no puede utilizarse para volver a discutir el interés superior del niño, cuestión que debe ser decidida por los tribunales del país de residencia habitual de éste, justamente el proceso que la Convención, con el retorno, busca asegurar ${ }^{70}$. Si las Cortes locales caen en la tentación de (re)

${ }^{66} \operatorname{Re} \mathrm{S}$ (minors), 2, FCR, 945, p. 954, 1994.

${ }^{67}$ Por ejemplo, Galit Moskowitz ilustra su preocupación con un caso en que la hija secuestrada por su madre, de nueve años, manifiesta su opinión en contra del retorno. Su crítica a la decisión de la corte inglesa no radica en la edad de la niña -que probablemente poseía madurez suficiente para manifestar su opinión en los términos de la Convención Internacional sobre Derechos del Niño- sino, más bien, en las razones que la llevaron a negarse al retorno: no le gustaba el colegio en Francia, su país de residencia habitual. Moskowitz (n. 59), p. 583. Que la opinión del menor deba evaluarse bajo los principios que gobiernan los objetivos de la Convención, no debe hacernos perder de vista que la excepción de "grave riesgo" es una y la oposición del niño, otra. Rania NANOs, "The Views of a Child: Emerging interpretation and significance of the child's objection defense under the Hague Child Abduction Convention", in Brooklyn Journal of International Law, vol. 22, Brooklyn, 1996, pp. 452-453, 460.

${ }^{68}$ Walshand \& SAVARd (n. 26), p. 46.

${ }^{69}$ NANOS (n. 67), pp. 463-464. Sobre la forma en que la ayuda técnica debe considerarse en la configuración del interés superior del niño, véase Domingo Lovera, "Razonamiento judicial y derechos del niño: de ventrílocuos y marionetas", en Justicia y Derechos del Niño, No 11, Bogotá, 2008, pp. 56-60.

${ }^{70}$ Friedrich (n. 59) ("This provision was not intended to be used by defendants as a vehicle to litigate (or relitigate) the child's best interests. Only evidence directly establishing 
evaluar las circunstancias en que se decretaron los derechos de custodia y visitas en el país de residencia habitual del hijo secuestrado, entonces el padre o la madre secuestradora se va a ver favorecida por su propio acto en contra de la Convención, incitando, además, un proceso de shopping de jurisdicciones. Es decir, de ir buscando cuáles son los países que interpretan de forma más amplia las excepciones del convenio para concretar el secuestro $^{71}$. Éste, si se quiere decir con estas palabras, es principalmente un instrumento "procedimental" para determinar la jurisdicción del país cuyas Cortes podrán evaluar y reconsiderar cuantas veces estimen conveniente el interés superior del niño ${ }^{72}$. Tal y como dispone el art. 1 de la Convención, su objetivo es hacer que los Estados contratantes respeten los derechos de custodia y visita ya establecidos en procedimientos judiciales desarrollados (aunque revocables) en otro país contratante -el país de residencia habitual del niño o niña-.

\section{2) La práctica doméstica: privilegiando la excepción}

Como hemos señalado, entonces, la práctica del Derecho Comparado ha sido la de interpretar la excepción del art. 13 letra b) en sentido estricto, en línea con los objetivos de la Convención. ¿¿ué ha ocurrido en Chile? No

the existence of a grave risk that would expose the child to physical or emotional harm or otherwise place the child in an intolerable situation is material to the court's determination. The person opposing the child's return must show that the risk to the child is grave, not merely serious") También Freeman (n. 22), p. 17 ("the Convention is quite clear that this defense is not to serve as a pretext for inquiring into the merits of the custody issue: it is not to be 'equated with "the best interest of the child" standard") y Moskowitz (n. 59), p. 585. Brenda Shirman detalla cómo -antes de la aprobación de la Convención- uno de los principales problemas radicaba, justamente, en la forma en que los tribunales de un país evaluaban, revisaban y alteraban decisiones sobre custodia y visitas ya definidas, invocando el interés superior del niño. Brenda Shirman, "International Treatment of Child Abduction and the 1980 Hague Convention”, in Suffolk Transnacional Law Journal, vol. 15, Boston, 1991, pp. 196-197.

${ }^{71}$ Moskowitz (n. 59), p. 581. También, Carrie Nelson, "Recent United States' interpretations of Article 13(B) of the Hague International Child Abduction Convention: we're on the right road", in Temple International and Comparative Law Journal, vol. 15, Philadelphia, 2001, pp. 307-308. Menos preocupada del shopping de jurisdicciones, Theresa Spinillo advierte que al momento de evaluar la excepción del art. 13 letra b) se estará de todas formas evaluando el interés superior del niño. Véase SPINiLlo (n. 62), p. 147-148 ("Es clara la Convención en prohibir a los jueces realizar decisiones de custodia sobre la base del interés superior del niño... Pero de allí no se sigue que el estándar del interés superior no deba ser considerado para otro tipo de procedimientos judiciales", como los que se promueven al amparo de la Convención). Se ha insistido, además, que el lenguaje similar entre la Convención de La Haya y la CDN en lo relativo a los intereses del menor, conspira en la confusión. LeGetTe (n. 56), p. 289.

${ }^{72}$ Moskowitz (n. 59), p. 585. 
es una coincidencia que en la doctrina extranjera se indique -a propósito de los problemas que plantea su aplicación práctica- que "Holanda, Brasil y Chile exigen más documentación de la prevista en el Convenio, como es la situación económica del solicitante" ${ }^{\text {". }}$. Ello presenta una manifestación clara respecto a cuál ha sido la tendencia jurisprudencial de nuestras Cortes superiores a la hora de conocer y juzgar conflictos relativos a secuestro internacional de niños.

Si bien nuestras Cortes deberían limitarse a verificar el cumplimiento de los presupuestos que establece la Convención para efecto que sea procedente ordenar el retorno inmediato, lo cierto es que los fallos recaídos en la materia demuestran una clara tendencia a desestimar el régimen remedial de retorno inmediato, basándose en consideraciones de fondo, que lleva a nuestros tribunales a revisar las decisiones dictadas por los tribunales extranjeros en que el menor secuestrado mantenía su residencia habitual o el régimen de cuidado personal compartido que se mantenía previo a la retención traslado ilícito. Es decir, en contra de los presupuestos y objetivos de la Convención.

La mayoría de las argumentaciones que se plasman en las decisiones de nuestras Cortes, giran en torno al mismo patrón argumental: y es que no cabe hacer una aplicación automática, mecánica e irreflexiva del convenio, 134 debiendo siempre verificarse si existe un grave riesgo de que el retorno exponga al niño a un peligro físico o moral. Hasta allí todo parecería adecuado; sin embargo, la interpretación se torna contraria a la Convención, en la medida de que dicho riesgo es ponderado como grave, a través de consideraciones que se alejan del espíritu de la misma, tales como probanzas relacionadas con informes sociales o sicológicos aportados por el padre o madre secuestrador(a), donde se consigna que es conveniente que los hijos se mantengan al cuidado de su madre, dado que ésta es una figura significativa en la vida y desarrollo de cualquier niño-todo lo anterior en contra de la tendencia comparada (IV. 1).

Es así que en una mayoría abrumadora de casos que llegan al conocimiento de nuestra Corte Suprema, a través de distintos recursos, se ha estimado que resulta aplicable la excepción contemplada en el art. 13 letra b), denegando así el retorno inmediato de los menores secuestrados. Ello, cuando ha sido acreditado que previo al traslado o retención ilícita, la custodia o cuidado de los hijos era compartida, y así, incluso, había sido regulada por los tribunales extranjeros. Esto implica que nuestra Corte, estando llamada tan sólo a verificar los presupuestos establecidos

${ }^{73}$ Rosa Lapiedra, "La sustracción de menores: el Convenio de La Haya de 25 de octubre de 1980", en Paz Lloria García, Secuestro de menores en el ámbito familiar: un estudio interdisciplinar, Madrid, Iustel 2008, p. 208. 
en la Convención para efecto de resolver si ha existido una retención o traslado ilícito, en la mayoría de los casos revisa aspectos distintos a los que le correspondería en estricto rigor, transformándose dichos juicios en procesos de discusión de cuidado personal o tuición, donde, finalmente, se privilegia nuestra tradicional concepción que los hijos están llamados en preferencia a vivir junto a la madre, por cuestiones de orden natural. Este tipo de decisiones se ve estimulada en un contexto como el chileno, que exhibe una gran cantidad de casos que se refieren a situaciones en que ha sido la madre quien ha trasladado o retenido ilícitamente al hijo, y no el padre, como pudiese haberse pensado en los orígenes de la Convención.

Es así que en un caso - que fue objeto de amplia cobertura periodística- la Corte estimó, respecto de la solicitud de regreso inmediato de un niño de cuatro años y nueve meses de edad -que

"si bien tanto la figura paterna y la materna son importantes y determinantes para su formación, lo cierto es que no puede desconocerse aquella regla natural o biológica que da cuenta de una especial vinculación con esta última"74.

La Corte concluyó:

"no puede desconocerse la relación filial que se ha desarrollado naturalmente entre la demandada y su hijo, conforme a la etapa de crecimiento que el mismo atraviesa y la importancia que tiene para su presente y futuro el mantener tal vinculación, en términos de no privar al menor de tener una vida al lado de su madre y bajo los cuidados cotidianos de la misma. Pues dicha pérdida o la posibilidad cierta de ello, representan un grave riesgo para el menor, en cuanto esa situación lo expone innegablemente a un peligro, sobre todo psicológico, en el ámbito de su desarrollo personal, el que atendidas las circunstancias ya descritas requiere la presencia de la figura materna, en los términos antes anotados" 75 .

Pues bien, la Corte Suprema en dicho caso -en que el cuidado personal del niño era compartido por ambos padres- sentenció que resultaba aplicable la excepción contemplada en el art. 13 b) ${ }^{76}$, teniendo en consi-

${ }^{74}$ Marcos Planella Goyta con Amaya Zubia Pinto, Corte Suprema de Chile, rol 22462009, 6 de julio de 2009, considerando décimo.

${ }^{75}$ Op. cit., cons. $11^{\circ}$.

${ }^{76}$ Dicha sentencia fue acordada con el voto en contra del abogado integrante señor Benito Mauriz, quien, en su opinión, se encontraba establecida la retención ilícita del menor por parte de su madre, así como la tuición compartida por ambos padres, por lo 
deración las eventuales consecuencias que se seguirían de una separación entre la madre y el hijo, a pesar de que la madre no se encontraba afecta a ningún impedimento para ingresar y permanecer en el país donde, previa a la retención ilícita, había mantenido la residencia habitual el menor. Es decir, en opinión de la Corte $-\mathrm{y}$ a pesar de verificar la ilicitud de la retención y prescindiendo que la tuición era compartida por ambos padres- estimó pertinente legitimar la conducta de la madre, alterando el régimen de custodia compartida (que ya no podría hacerse efectivo), todo en desmedro del padre.

Es más; uno podría preguntarse, entonces, ¿̇cuándo podría proceder a la luz de la interpretación que efectúa la Corte Suprema del artículo 13 b) de la Convención, el retorno inmediato del niño? Si estamos ante un caso en que no existen ni alegaciones ni pruebas en contra del padre recurrente que pudiesen configurar una situación de peligro físico o sicológico para el hijo, y la Corte de todas formas entiende que la mera separación configura la excepción, entonces en Chile el retorno no procedería nunca-o en muy pocos casos. En efecto, el padre o madre que ha estado dispuesto a alejar al niño de su otro progenitor, eventualmente se encontraría llano, también, a imputarle al otro padre una serie de conductas impropias (sean falsas o no), con el objetivo de configurar la excepción de riesgo o peligro ante el 136 retorno; o de presionarlo para que en su declaración manifestase su voluntad de seguir residiendo en Chile, para efecto de solicitar la aplicación de la excepción del art. 13 b) de la Convención.

Además, cabe anotar que el alto estándar probatorio exigido al efecto también se aleja de los objetivos de la Convención. Ello queda de manifiesto en votos de minoría plasmados en algunos fallos, donde se indica que no existen antecedentes o probanzas objetivas en el proceso que permitan configurar la excepción contenida en el art. 13 b) de la Convención ${ }^{77}$. Cuando las Cortes razonan en los términos antes dichos, las sentencias se transforman en pronunciamientos acerca de cuál es el mejor lugar para que viva el niño o niña, lo cual se aleja del espíritu del convenio, que en carácter de excepcional y en términos restrictivos, otorgó facultades a los tribunales de la autoridad requerida para no decretar el regreso inmediato (justamente para evitar la tendencia nacionalista que pueda existir en estos casos, y la tendencia a privilegiarse la residencia en el estado contratante requerido).

que ninguno de éstos se encontraba facultado para alterar la situación del hijo común en desmedro de los derechos del otro progenitor.

${ }^{77}$ Véase: (a) Voto de contra de abogado integrante señor Benito Mauriz en Marcos Planella... (n. 74). (b) Voto en contra de ministro señor Urbano Marín Vallejo en Shrayef Paredes Kamal y Otra, Corte Suprema de Chile, rol 1231-2004, 17 de mayo de 2004. (c) Voto en contra de Ministro señor Urbano Marín Vallejo en Mira Casas Cordero, Corte Suprema de Chile, rol 4533-2005, 16 de noviembre de 2005. 
Finalmente, de acuerdo con lo anterior, se arriba a un absurdo, éste es, que en algunos casos resultará más conveniente, para el padre o madre que consiga un cuidado personal compartido en un país extranjero y que pretenda modificar dicha situación, secuestrar al hijo en Chile, que intentar un juicio de modificación del cuidado compartido, en el país de residencia habitual del niño. La interpretación extremadamente amplia que efectúa la Corte Suprema de dicha excepción es la que posibilita que se configuren situaciones como las descritas, en desmedro del padre o madre que ve sus derechos -legalmente definidos- alterados de facto, al tiempo que se subvierte la Convención, sus razones justificatorias y los principios que la inspiraron. Así, como resulta fácil advertir, razonamientos de este tipo alientan el forum-shopping de jurisdicciones y terminan, al fin del día, favoreciendo al padre o madre secuestrador, esto es, una pura situación de hecho que es, justamente, lo que la Convención pretendía evitar.

Por lo anterior, parece necesario y urgente que nuestras Cortes adopten una tendencia jurisprudencial orientada, ante todo, a desincentivar el secuestro internacional de niños, lo cual necesariamente va de la mano con una interpretación restrictiva de la excepción contenida en el art. 13 b) de la Convención.

\section{Conclusiones}

Nuestra legislación establece diferencias claras entre el derecho-deber de cuidado personal de los hijos, por una parte, y el derecho-deber a mantener un régimen de relación directa y regular con éstos, por otra. El primero, como se ha señalado, otorga al padre titular del mismo el deber de asegurar la crianza y la educación del hijo(a). El segundo, en cambio, reconoce el derecho de este último a mantener un contacto regular con su padre o madre con el cual no convive.

Los contornos de estos derechos, hemos argumentado, se alteran en el contexto internacional. Cuando el derecho a mantener un régimen de relación directa y regular va acompañado de una cláusula ne exeat, que en el caso de Chile opera por la sola disposición de la ley, entonces el padre o madre titular de derechos de visita puede adoptar decisiones que, tradicionalmente, se encontraban alojadas bajo el paraguas del cuidado personal (en la práctica estadounidense la joint legal custody).

En efecto, el padre o madre titular del régimen de relación directa y regular se encuentra facultado para decidir el lugar de residencia de su hijo, con el cual no vive, toda vez que es de su resorte autorizar su salida del país. En el Derecho Comparado, esta facultad es más que un simple veto. Y, todavía más, a la luz de la Convención de la Haya configura derechos 
de cuidado personal -que permiten reclamar el retorno inmediato del niño secuestrado.

Esta interpretación, cada vez más uniforme en el Derecho Comparado, debe llamarnos la atención acerca de sus cuestiones cruciales. La primera, es que Chile debiera avanzar hacia el reconocimiento legal del cuidado personal compartido o, al menos, regular la posibilidad del padre no custodio de participar en las decisiones referentes a la vida del hijo (corresponsabilidad parental). Si el padre no titular del derecho al cuidado personal puede, de todas formas, determinar el lugar de residencia del niño, ello nos debería llevar a pensar -a la luz de nuestro ordenamiento jurídico actual- que él mismo puede intervenir también en todas las decisiones relevantes en la vida de éste, y no transformarse en un mero espectador de ella.

Así, debería concluirse que la definición de cuidado personal se encuentra relacionada más bien con la convivencia física de la madre o el padre, titular del derecho de tuición, con el hijo-lo que, como hemos señalado, en la práctica estadounidense corresponde a la joint physical cusotdy o tuición física, sin excluir el derecho de intervención del otro en las decisiones relevantes de la vida de los niños. Ello es lo que ocurre, finalmente, cuando se determina el lugar de residencia de éstos, ya sea en el extranjero o dentro del mismo territorio nacional.

138 En segundo lugar, y habida cuenta que hemos insistido en los objetivos y principios fundantes de la Convención de la Haya, debe repensarse la forma en que nuestra jurisprudencia se ha acercado a la decisión de casos sobre secuestro internacional. Nuestra Corte Suprema, en oposición a los objetivos explícitos de dicho convenio -que llaman a desincentivar los secuestros- ha privilegiado la aplicación de las excepciones por sobre el retorno inmediato. No es que dichas excepciones no se contemplen en la Convención, como hemos indicado. Sino, cosa distinta, que nuestra jurisprudencia se acerque inadecuadamente a las excepciones-transformándolas en la regla general-al tiempo que se inmiscuye de forma indebida en decisiones soberanas adoptadas por otras jurisdicciones, mejor preparadas que la nuestra para determinar los derechos y deberes de los padres, así como para tutelar el interés superior del niño involucrado. Sostener lo contrario, implica ratificar beneficios personales a partir de actuaciones ilegales, esto es, legitimar la situación de hecho. Chile, en este contexto, y en contra de los objetivos planteados en la Convención, corre el riesgo de transformarse, justamente, en un paraíso para el secuestro de niños. 


\section{BiBLIOGRAFÍA}

Abbott v. Abbott, 542, F.3d, 1081, $5^{\text {th }}$ Cir., 2008.

Abbott $v$. Abbott, 560, U.S., 2010, disponible online en: http://www.supremecourt. gov/ opinions/09pdf/08-645.pdf.

Audiencia Provincial de Barcelona, Juicio No 338/08 JUR 2009/394078 (2009).

Audiencia Provincial de Sevilla, juicio No 36/08 JUR 2009/314040, 2009.

Aust, Anthony, Handbook of International Law, Cambridge, Cambridge University Press, 2010.

BASS, Sara, "Ne exeat clauses proven ineffective: how the Hague Convention renders access rights illusory", in North Carolina Journal of International Law and Commercial Regulation, vol. 29, Chapel Hill, 2004.

Black's Law Dictionary, St. Paul, Thomson West, 2006.

Bruch, Carol, "The Hague Child Abduction Convention: past, accomplishments, future challenges", in Sharon Detrick \& Paul Vlaardingerbroek (eds.), Globalization of Child Law: The role of the Hague Conventions, Hague, Martinus Nijhoff Publishers, 1999.

Cillero, Miguel, "Interés superior del niño en el marco de la Convención Internacional sobre los Derechos del Niño", en Revista Justicia y Derechos del Niño, vol. 1, Santiago, 1999.

Convención de la Haya sobre Aspectos Civiles de la Sustracción de Menores, 25.Oct.1980, La Haya, en vigor en Chile desde el 1 de mayo de 1994 (D. Of. 17 junio 1994), http://hcch.e-vision.nl/index_en.php?act=conventions.status $\& \operatorname{cid}=24$.

Corte de Apelaciones de Ontario, Pollastro v. Pollastro, 171, D.L.R., $4^{\text {th }}$ 32, 1999.

Corte de Apelaciones de Santiago, en Revista Derecho y Jurisprudencia, No 2, Santiago, 2004, sec. $2^{\mathrm{a}}$.

Corte Suprema de Canadá, Thompson $v$. Thompson, 3, S.C.R. 551, 1994.

Croll v. Croll, F.3d, 133, $2^{\mathrm{d}}$ Cir., 2000.

Fawcett v. McRoberts, 326, F.3d, 491, $9^{\text {th }}$ Cir., 2001.

Freeman, Michael, A commentary on the United Nations Convention on the Rights of the Child. Article 3: The Best Interest of the Child, Leiden, Martinus Nijhoff Publishers, 2007.

Friedrich $v$. Friedrich, 78 F.3d, 1060, 1996.

Furnes $v$. Reeves, 362, F.3d, 702, $11^{\text {th }}$ Cir., 2004.

Gómez, Blanca, Aspectos civiles de la sustracción de internacional de menores: problemas de aplicación del Convenio de la Haya de 25 de octubre de 1980, Madrid, Dykinson, 2002.

Gonzalez v. Gutierrez, 311, F.3d, 942, $9^{\text {th }}$ Cir., 2002.

GuPTE, Arpita, "International Law: Rights of access with ne exeat clause do not create rights of custody under Hague Convention-Abbott v. Abbott, 542 F.3d 
1081 (5 $5^{\text {th }}$ Cir. 2008)", in Suffolk Transnational Law Review, vol. 33, No 1 , Boston, 2010.

JACKSON, Jane, "Interpreting ne exeat rights as rights of custody: the United States supreme Court's chance to advance the purposes of the Hague Convention on International Child Abduction", in Tulane Law Review, vol. 84, New Orleans, November, 2009.

LApiedra, Rosa "La sustracción de Menores: el Convenio de La Haya de 25 de octubre de 1980", en Paz Lloria García, Secuestro de menores en el ámbito familiar: un estudio interdisciplinar, Madrid, Iustel, 2008.

LATHrop, Fabiola, "La corresposabilidad parental", en Gonzalo Figueroa y Mauricio TAPIA, Estudios de Derecho Civil: IVJornadas de Derecho Civil, Santiago, Abeledo Perrot Legal Publishing, 2009.

LeGette, Caroline, "International Child Abduction and the Hague Convention: emerging practice and interpretation of the discretionary exception", in Texas International Law Journal, Texas, 1990.

LoverA, Domingo, "Razonamiento judicial y derechos del niño: de ventrílocuos y marionetas", en Justicia y Derechos del Niño, No 11, Bogotá, 2008.

Manuel Martínez Guillén con Georgina Pérez de Arce Morcom, Corte de Apelaciones de San Miguel de fecha 15 de mayo del año 2001.

Marcos Planella Goyta con Amaya Zubia Pinto, Corte Suprema de Chile, rol 140 2246-2009, 6 de julio de 2009.

Mira Casas Cordero, Corte Suprema de Chile, rol 4533-2005, 16 de noviembre de 2005.

Monfort, María Jesús, "Algunas cuestiones civiles en torno a la sustracción de menores en el ambito familiar", en Paz Lloria GARCía (ed.), Secuestro de menores en el ambito familiar: un estudio interdisciplinar, Madrid, Iustel, 2008.

Moskowitz, Galit, "The Hague Convention on International Child Abduction and the Grave Risk of Harm Exception. Recent decisions and their implications on children from nations in political turmoil", in Family Court Reviere, vol. 41, New York, 2003.

NAnos, Rania, "The Views of a Child: Emerging interpretation and significance of the child's objection defense under the Hague Child Abduction Convention", in Brooklyn Journal of International Law, vol. 22, Brooklyn, 1996.

Nelson, Carrie, "Recent United States' interpretations of Article 13(B) of the Hague International Child Abduction Convention: we're on the right road", in Temple International and Comparative Law Journal, vol. 15, Philadelphia, 2001.

NeLSON, Sharon, "Turning our backs on the children: implications of recent decisions regarding the Hague Convention on International Child Abduction", in University of Illinois Law Review, vol. 2001, No 2, Champaign, 2001.

O' Connor, Kathleen, "What gives you the right?! Ne exeat rights should constitute rights of custody after Furnes v. Reeves", in Penn State International Law Review, vol. 24, Pennsylvania, 2005. 
Pérez Vera, Elisa, "Informe explicativo de la Convención de la Haya de 1980 sobre Secuestro de Niños", in Hague Conference on Private International Law, 1982, disponible en: http://www.hcch.net/index_en.php?act=publications. details\&pid $=2779$.

Re S (minors), 2, FCR, 945, p. 954, 1994.

Rodríguez, María, Cuidado personal de niños y adolescentes en el nuevo Derecho chileno de Familia, Santiago, Abeledo Perrot Legal Publishing, 2010.

Schnitzer-ReEse, Ericka, "International Child Abduction to Non-Hague Convention Countries: The need for and International Family Court", in Northwestern University Journal of International Human Rights, vol. 2, Chicago, april 2004, disponible en: http://www.law.northwestern.edu/journals/JIHR/v2/7.

Shirman, Brenda, "International Treatment of Child Abduction and the 1980 Hague Convention”, in Suffolk Transnacional Law Journal, vol. 15, Boston, 1991.

Shrayef Paredes Kamal y otra, Corte Suprema de Chile, rol 1231-2004, 17 de mayo de 2004.

Silberman, Linda, "Interpreting the Hague Abduction Convention: In Search of a Global Jurisprudence", in New York University Public Law and Legal Theory Working Papers, Paper 18, New York, 2006, disponible en: http://lsr.nellco. org/nyu_plltwp/18.

Spinillo, Theresa, "The Hague Convention on the Civil Aspects of International Child Abduction: An analysis of the grave risk harm defense", in New York International Law Review, vol. 14, New York, 2001.

WALDROn, Jeremy, "Foreign Law and the Modern Ius Gentium", in Harvard Law Review, vol. 119, N 1, Cambridge, 2005.

Walshand, Michael \& Susan Savard, "International Child Abduction and the Hague Convention", in Barry Law Review, Orlando, vol. 6, 2006.

Wills, Melissa S., "Interpreting the Hague Convention on International Child Abduction: why American courts need to reconcile the rights of non-custodial parents, the best interests of abducted children, and the underlying objectives of the Hague Convention", in Review of Litigation, vol. 25, Texas, 2006. 